\title{
Liver transplantation for advanced hepatocellular carcinoma
}

\author{
Hae Won Lee ${ }^{1,2}$, and Kyung-Suk Suh' \\ 'Department of Surgery, Seoul National University College of Medicine, Seoul, ${ }^{2}$ Department of Surgery, Seoul National University \\ Boramae Medical Center, Seoul, Korea
}

There has been ongoing debate that the Milan criteria may be too strict that a significant number of patients who could benefit from liver transplantation (LT) might have been excluded. Based on this idea, various studies have been conducted to further expand the Milan criteria and give more HCC patients a chance of cure. In deceased donor LT (DDLT) setting, expansion of the criteria is relatively tempered because the results of $L T$ for HCC should be comparable to those of patients with non-malignant indications. On the other hand, in living donor LT (LDLT) situation, liver grafts are not public resources. The acceptable target outcomes for LDLT might be much lower than those for DDLT. Patients with biologically favorable tumors might have excellent survivals after LT despite morphological advanced HCCs. Therefore, the significance and utility of biological tumor parameters for selecting suitable LT candidates have been increased to predict HCC recurrence after LT. Although there is no consensus regarding the use of prognostic biomarkers in LT selection criteria for HCC, the combination of conventional morphological parameters and new promising biomarkers could help us refine and expand the LT criteria for HCC in the near future. (Clin Mol Hepatol 2016;22:309-318)

Keywords: Carcinoma; Hepatocellular; Transplantation, Liver; Selection Criteria; Expanded criteria; Biomarker

\section{INTRODUCTION}

Hepatocellular carcinoma (HCC) is the sixth most common malignant tumor worldwide and the third leading cause of cancer-related death.' Liver transplantation (LT) is one of the accepted treatment modalities for HCC. ${ }^{2}$ This modality can be offered to patients with unresectable HCC regardless of patients' liver function. ${ }^{3}$ It can also treat the underlying liver disease and consequently decrease the risk of de novo HCC.,

However, LT for advanced HCC might not be justified due to high recurrence rate and poor in the era of organ shortage. In 1996, Mazzaferro and colleagues ${ }^{6}$ suggested the Milan criteria for
LT selection, i.e., LT should be limited to patients with early HCC defined as a single tumor $\leq 5 \mathrm{~cm}$ or no more than three tumors $\leq 3 \mathrm{~cm}$ in diameter without major vessel invasion or extrahepatic tumor spread. In these Milan criteria, the 4-year overall and recurrence-free survivals after LT were $75 \%$ and $83 \%$, respectively. The Milan criteria are still considered as the gold standard for selecting for LT for HCC.

Because LT is undoubtedly the only chance of cure for HCC patients with advanced cirrhosis, many expanded criteria have been proposed with the intent to increase the number of transplantable patients. ${ }^{5}$ Up to now, none of them has been recognized as a valid substitute of the Milan criteria. 'Many centers worldwide have

\footnotetext{
Abbreviations:

AFP, alpha-fetoprotein; CRP, C-reactive protein; DCP, des-gamma-carboxy prothrombin; DDLT, deceased donor liver transplantation; HCC, hepatocellular carcinoma; LDLT, living donor liver transplantation; LRT, locoregional treatment; LT, liver transplantation; NLR, neutrophil-to-lymphocyte ratio; PET, positron emission tomography; PLR, platelet-to-lymphocyte ratio; SUVmax, maximal standardized uptake value; UCSF, the university of California San Francisco
}

\section{Corresponding author: Kyung-Suk Suh}

Department of Surgery, Seoul National University College of Medicine Seoul National University Hospital, 101 Daehak-ro, Jongno-gu, Seoul 03080, Korea

Tel: +82-2-2072-3789, Fax: +82-2-766-3975

E-mail:kssuh@snu.ac.kr 
developed the expanded criteria of their own. Some of them use biological parameters as well as conventional morphological factors to select patients suitable to $\mathrm{LT}^{5}{ }^{5}$ The increasing importance of biologic parameters is leading to a paradigm shift in LT patient selection criteria. This article aims at reviewing new strategies proposed to perform LT for more advanced HCC.

\section{DEBATE ON THE MILAN CRITERIA}

The initial experiences of LT for HCC were disappointing due to high recurrence rates and poor survivals after LT. ${ }^{7-11}$ In 1985, Starzl's group $^{7}$ reported a recurrence rate of $75 \%$ in patients who had LT due to hepatic malignancies and lived for at least 2 months after LT. Bismuth and colleagues ${ }^{11}$ also reported a $47 \%$ of 3-year survival rate from their experience of 60 LTs for HCC patients. Because the survivals of $\mathrm{LT}$ for $\mathrm{HCC}$ are worse than those for other etiologies and there is a donor organ shortage for the potential recipients, LT for HCC has not been treated properly for many years. ${ }^{12}$

The advent of the Milan criteria was one of epoch-making events in the history of LT. Since 1996, those criteria have been validated by many other centers worldwide. Patients who met Milan criteria and underwent LT could have post-transplant survival rates comparable to patients transplanted for non-tumor indications. ${ }^{13}$ Thus, the Milan criteria justified LT for HCC and became a universal standard of LT patient selection criteria.

Nevertheless, there has been ongoing debate regarding modifications of the criteria. ${ }^{3}$ The attempts to expand the criteria are based on the idea that the Milan criteria may be too restrictive that a significant number of HCC patients who could benefit from LT might have been excluded. According to the Milan criteria, only $6 \%$ of patients with HCC would be eligible for LT. ${ }^{14,15}$ Everyone with HCC beyond the Milan criteria does not have recurrence after LT. In addition, a significant proportion of those patients could still benefit from LT without increasing HCC recurrence rates. ${ }^{15,16}$ Therefore, researchers have continuously tried to expand the Milan criteria with acceptable post-transplant survivals. Various selection criteria with different strategies have been suggested up to now.

\section{EXPANSION OVER THE MILAN CRITERIA}

There have been many attempts to expand the Milan criteria (Table 1). ${ }^{17-28}$ The most representative expanded criteria were the University of California San Francisco (UCSF) criteria proposed by
Yao and colleagues ${ }^{29}$ in 2001. Based on pathologic data of 70 patients transplanted for HCC, they made an extension of the selection criteria to be a tumor $6.5 \mathrm{~cm}$ or less in diameter, or two to three tumors with each $4.5 \mathrm{~cm}$ or less in diameter and a total diameter of $8 \mathrm{~cm}$ or less. ${ }^{29}$ Patients within the UCSF criteria had 1and 5 -year survivals of $90 \%$ and $75 \%$. However, patients beyond the criteria had a 1-year survival of $50 \% .{ }^{29}$ These results were validated prospectively based on pre-LT imaging by the same group. The 5 -year recurrence rate was only $9.1 \%$ and the respective survival rate without recurrence was $80.7 \%$ within their criteria. ${ }^{17}$ More recently, the validity of the USCF criteria was confirmed in the United Network for Organ Sharing database..$^{30}$ In this large scale analysis, the survival of 59 patients beyond the Milan criteria but within the USCF was not inferior to that of 1,913 patient within the Milan criteria (1-, 2-, 3- and 4-year survival rates: $91 \%, 80 \%$, 68 , and $51 \%$ versus $89 \%, 81 \%, 76 \%$, and $72 \%$, respectively, $P=0.21) .{ }^{30}$ However, the beneficial effect of extension to the UCSF criteria might not be large. In that study, only 59 patients (3.0\%) of those who were beyond the Milan criteria were included within the USCF criteria. ${ }^{30}$ Hence, many centers have not yet accepted the UCSF criteria as a replacement for the Milan criteria. ${ }^{12}$

Mazzaferro and colleagues ${ }^{18}$ have suggested a new set of criteria, known as the 'Up-to-seven' criteria from a web based survey of patients transplanted for HCC beyond the Milan criteria. They extended the criteria up to tumors with seven as the sum of the size of the largest tumor (in $\mathrm{cm}$ ) and the number of tumors using the concept of "Metroticket". Patients within the Up-to-seven criteria without microvascular invasion had a 5 -year overall survival rate of $71 \%$, which was comparable to the previous results based on the Milan criteria. ${ }^{18}$ However, the 5 -year survival fell down to $47 \%$ for patients with microvascular invasion. ${ }^{18}$ Unfortunately, it is difficult to confirm the presence of microvascular invasion before LT.

Toso and colleagues ${ }^{22}$ have suggested to use total tumor volume instead of size and number to predict the risk of recurrence. However, this approach could be limited because the total tumor volume was derived from the diameter rather than actually measured. ${ }^{12}$ Hanzhou and Toronto groups added tumor biopsy in their selection criteria. ${ }^{23,24}$ They added the preoperative biopsy in cases with advanced HCC while extending the upper limit of the size and number of tumors permitted. However, using preoperative biopsy is controversial because it is a risky procedure to patients with advanced cirrhosis.

In many Asian countries, living donor LT (LDLT) accounts for the majority of $L T$ cases. Therefore, the landscape of $L T$ in Asia differs from that in Western countries. ${ }^{27}$ Because liver grafts for LDLT are 
Table 1. Expanded criteria and reported outcomes

\begin{tabular}{|c|c|c|c|c|}
\hline Authors (year) & Eligibility criteria & $\begin{array}{l}\text { Conditions and number of } \\
\text { patients included }\end{array}$ & $\begin{array}{l}\text { 5-year overall } \\
\text { survival rate } \\
(\%)\end{array}$ & $\begin{array}{l}\text { 5-year } \\
\text { recurrence- } \\
\text { free rate }{ }^{*}(\%)\end{array}$ \\
\hline $\begin{array}{l}\text { Yao, et al. }{ }^{17}(2007) \\
\text { USCF } \text { criteria }^{\circ}\end{array}$ & $\begin{array}{l}1 \text { tumor } \leq 6.5 \mathrm{~cm} \text {, or } 2-3 \text { tumors } \leq 4.5 \mathrm{~cm} \\
\text { with total tumor diameter } \leq 8 \mathrm{~cm}\end{array}$ & Within the expanded $(n=168)$ & $\begin{array}{l}81 \text { (without } \\
\text { recurrence) }\end{array}$ & 91 \\
\hline \multirow[t]{2}{*}{$\begin{array}{l}\text { Mazzaferro, et al. }{ }^{18} \\
\text { (2009) } \\
\text { Up-to-seven criteria }\end{array}$} & $\begin{array}{l}\text { Sum of the number of tumors and diameter } \\
\text { of the largest tumor (in } \mathrm{cm} \text { ) } \leq 7\end{array}$ & $\begin{array}{l}\text { Within the expanded, beyond } \\
\text { the Milan criteria and without } \\
\text { microvascular invasion ( } n=283 \text { ) }\end{array}$ & 71 & 91 \\
\hline & & $\begin{array}{l}\text { Within the expanded, beyond the } \\
\text { Milan criteria and with microvascular } \\
\text { invasion ( } n=116)\end{array}$ & 47 & 60 \\
\hline Herrero, et al..$^{19}(2008)$ & 1 tumor $\leq 6 \mathrm{~cm}$, or $2-3$ tumor $\leq 5 \mathrm{~cm}$ & $\begin{array}{l}\text { Within the expanded, beyond the } \\
\text { Milan criteria }(n=24)\end{array}$ & 78 & \\
\hline Silva, et al. ${ }^{20}(2008)$ & $\begin{array}{l}\text { Up to } 3 \text { tumors with the maximum diameter } \\
\leq 5 \mathrm{~cm} \text {, and total tumor diameter } \leq 10 \mathrm{~cm}\end{array}$ & $\begin{array}{l}\text { Within the expanded, beyond the } \\
\text { Milan criteria }(n=26)\end{array}$ & 69 & \\
\hline $\begin{array}{l}\text { Lee, et al. }{ }^{21} \text { (2008) } \\
\text { Asan criteria }\end{array}$ & $\begin{array}{l}\text { Up to } 6 \text { tumors with the maximum diameter } \\
\leq 5 \mathrm{~cm}\end{array}$ & Within the expanded $(n=186)$ & 76 & 85 \\
\hline Toso, et al. ${ }^{22}$ (2008) & Total tumor volume $\leq 115 \mathrm{~cm}^{3}$ & Within the expanded $(n=251)$ & 80 & 87 \\
\hline $\begin{array}{l}\text { Zheng, et al. }{ }^{23} \text { (2008) } \\
\text { Hanzhou criteria }\end{array}$ & $\begin{array}{l}\text { Total tumor diameter } \leq 8 \mathrm{~cm} \text {, or total tumor } \\
\text { diameter }>8 \mathrm{~cm} \text {, with pathologic grade I } \\
\text { or } \| \text { on biopsy and AFP } \leq 400 \mathrm{ng} / \mathrm{mL}\end{array}$ & Within the expanded ( $n=99)$ & 71 & 62 \\
\hline $\begin{array}{l}\text { Dubay, et al. } .^{24}(2011) \\
\text { Toronto criteria }\end{array}$ & $\begin{array}{l}\text { Any size and number, and not poorly } \\
\text { differentiated histology on biopsy (beyond } \\
\text { the Milan criteria only) }\end{array}$ & Within the expanded $(n=294)$ & 72 & 68 \\
\hline $\begin{array}{l}\text { Shirabe, et al. }{ }^{25} \text { (2011) } \\
\text { Kyushu criteria }\end{array}$ & $\begin{array}{l}\text { Any number of tumors with the maximum } \\
\text { diameter }<5 \mathrm{~cm} \text { or } \mathrm{DCP}^{\S}<300 \mathrm{mAU} / \mathrm{mL}\end{array}$ & $\begin{array}{l}\text { Within the expanded, beyond the } \\
\text { Milan criteria }(n=48)\end{array}$ & & 80 \\
\hline $\begin{array}{l}\text { Kaido, et al. }{ }^{26}(2013) \\
\text { Kyoto criteria }\end{array}$ & $\begin{array}{l}\text { Up to } 10 \text { tumors with the maximum diam- } \\
\text { eter } \leq 5 \mathrm{~cm} \text { and } \mathrm{DCP} \leq 400 \mathrm{mAU} / \mathrm{mL}\end{array}$ & $\begin{array}{l}\text { Within the expanded, beyond the } \\
\text { Milan criteria }(n=147)\end{array}$ & 82 & 96 \\
\hline $\begin{array}{l}\text { Akamatsu, et al. }{ }^{27} \\
\text { (2014), Tokyo criteria }\end{array}$ & $\begin{array}{l}\text { Up to } 5 \text { tumors with the maximum diameter } \\
\leq 5 \mathrm{~cm}\end{array}$ & Within the expanded $(n=118)$ & 80 & \\
\hline $\begin{array}{l}\text { Kim, et al. }{ }^{28}(2014) \\
\text { Samsung criteria }\end{array}$ & $\begin{array}{l}\text { Up to } 7 \text { tumors with the maximum diameter } \\
\leq 6 \mathrm{~cm} \text { and } A F P^{\ddagger} \leq 1,000 \mathrm{ng} / \mathrm{mL}\end{array}$ & Within the expanded $(n=152)$ & & 84 \\
\hline
\end{tabular}

*The recurrence of hepatocellular carcinoma was considered as an event but patient death was censored.

${ }^{\dagger}$ University of California, San Francisco.

${ }^{\ddagger}$ Alpha-fetoprotein.

§Des-gamma-carboxy prothrombin.

not limited by the organ allocation system, most Asian LDLT centers have actually developed and applied more expanded criteria. $5,27,31$ The Asan criteria proposed by Lee and colleagues ${ }^{21}$ in 2008 have up to 5 nodules with a maximum diameter of $6 \mathrm{~cm}$. In their study, the 5-year survival rate of patients within the Asan criteria was $76 \%$, similar to that of patients within the Milan criteria. ${ }^{21}$ The principle criteria of the Tokyo group for LDLT for HCC were reported to be up to five nodules with a maximum diameter of 5 $\mathrm{cm}^{27}$ In their series, the expanded selection criteria did not worsen post-transplant prognosis compared to the Milan criteria. ${ }^{27}$

Some other centers in Asia have proposed further expansion of the selection criteria of LDLT for HCC using tumor markers. ${ }^{25,26,28}$ The Kyoto group has proposed new expanded criteria by adding serum des-gamma-carboxy prothrombin (DCP) level to the selection criteria while increasing the upper limit of the number of tumors to 10 . These criteria were defined as 10 or less tumors at 5 $\mathrm{cm}$ or less in diameter with serum DCP levels of $400 \mathrm{mAU} / \mathrm{mL}$ or less. ${ }^{26}$ The Kyushu group removed the limitation of the number of tumors in their expanded criteria. All HCCs with the largest diameter of less than $5 \mathrm{~cm}$ or with DCP level of less than $300 \mathrm{mAU} / \mathrm{mL}$ were included in their selection criteria. ${ }^{25}$ The Samsung group of Korea used alpha-fetoprotein (AFP) instead of DCP to expand the 
selection criteria. They suggested that LDLT could be reasonably performed for HCC patients with no more than seven tumors at 6 $\mathrm{cm}$ or less in diameter with serum AFP level of $1000 \mathrm{ng} / \mathrm{mL}$ or less. ${ }^{28}$ Using the Kyushu and Samsung criteria, the 5 -year posttransplant recurrence-free rates were $80 \%$ and $84 \%$, respectively, which were similar to the original result ( $83 \%$ at 4 -years after LT) of the Milan group. ${ }^{25,28}$ These results suggested that we could extend the upper limits of tumor size and number of transplantable HCCs by using tumor markers such as AFP or DCP.

To date, although several expanded criteria have been proposed, only the Milan criteria have been widely validated and accepted as the gold standard worldwide. ${ }^{27}$ It may be because universally acceptable criteria should be based on objective parameters that could be easily measured before LT and the cutoff value of which should be derived from robust statistical methods. ${ }^{15}$ Moreover, the ideal criteria should yield similar overall and recurrence-free survival rates as the Milan criteria, particularly in deceased donor LT (DDLT). Although intrahepatic tumor burden allowed and the use of biopsy or tumor markers for patient selection are matters of debate, it is a generally agreeable to exclude HCC patients with macrovascular invasion or extrahepatic disease..$^{15}$

\section{BIOLOGICAL PARAMETERS PREDICTING HCC RECURRENCE AFTER LIVER TRANSPLANTA- TION}

\section{Histopathological features}

The size and number of tumors and the presence of macrovascular invasion are well-known predictors of HCC recurrence after LT. Most expanded criteria are based on the size and the number of tumors, similar to the Milan criteria, although they have attempted to further extend the upper limit. In addition, macrovascular invasion is still considered as a contraindication for LT in most centers. Morphological parameters are very suitable for selecting LT candidates because they are not only strongly correlated with post-LT recurrence, but also easily measured preoperatively by imaging modalities. However, gross morphology of tumors may not appropriately reflect the biological behavior and aggressiveness of tumors. ${ }^{32}$ Some patients have good survival after LT despite morphologically advanced HCC. Thus, recent studies for criteria expansion have been focused on preoperative assessment of tumor biology to correctly stratify the recurrence risk after LT.
Histopathologic features such as microvascular invasion and tumor differentiation are evident predictors of post-LT recurrence. ${ }^{33-35}$ Some LT centers including the Hanzhou and Toroto groups have emphasized the necessity of selective preoperative biopsy to assess pathologic feature. ${ }^{23,24,36}$ However, preoperative needle biopsy may increase tumor seeding and post-LT recurrence. In addition, it can cause bleeding in cirrhotic patients. ${ }^{37,38}$ Furthermore, not only the presence of microvascular invasion, but also dominant differentiation grade of tumors may not be reliably assessed before LT in spite of invasive biopsy procedure. ${ }^{39,40}$ Hence, biomarkers strongly correlated with these histopathologic features may be actually more helpful in patient selection than preoperative biopsy.

\section{Tumor markers}

Tumor markers are biological parameters that can be easily checked. AFP is the most well-known tumor marker for HCC. Because a strong correlation between this tumor marker and $\mathrm{HCC}$ recurrence after $\mathrm{LT}$ has been suggested in many studies, ${ }^{23,41-45}$ AFP is considered as an independent predictive factor of post-LT outcomes without any doubt. ${ }^{32}$ However, greatly various cutoff values (from 100 to $1,000 \mathrm{ng} / \mathrm{mL}$ ) of AFP level have been proposed according to different studies. None of them has been validated internationally. ${ }^{28,42,43,46-48}$ Interestingly, some studies have suggested that the slope of AFP progression before LT could have a predictive power of HCC recurrence after $\mathrm{LT}^{49-51}$ The correlation between dynamic AFP and post-LT outcomes has not been studied sufficiently compared to static AFP. In addition, there is no general consensus on the definition or cutoff value of dynamic AFP to adopt.' Nonetheless, dynamic AFP level could be worth of further study because it may be able to show tumor activity and aggressiveness better than static AFP at some points.

Another tumor marker for HCC that is recently utilized is DCP. It is also known as the protein induced by vitamin $\mathrm{K}$ absence or antagonist II. Preoperative serum DCP level has been reported to be a possible indicator of microvascular invasion in HCC $^{52-54}$ The correlation between high DCP levels and HCC recurrence after $\mathrm{LT}$ has been suggested in recent Japanese studies. ${ }^{55-57}$ The Kyoto group and Kyushu group have already updated their selection criteria including pre-transplant DCP level as mentioned earlier. ${ }^{25,26}$ They showed that patients beyond the Milan criteria but within their criteria (with low DCP level $<300$ or $400 \mathrm{mAU} / \mathrm{mL}$ ) could have excellent prognosis after $\mathrm{LT}$. Therefore, DCP may be a promising predictor of HCC recurrence after LT in spite of fewer global evidenc- 
Hae Won Lee, et al. Liver transplantation for advanced HCC

es compared to AFP.

Interestingly, the recent Korean multicenter study developed a new scoring system to predict post-LT recurrence for patients with advanced HCC using square-root values of AFP and DCP. Based on Cox proportional hazards model, the risk score system called MoRAL score was calculated as $11 \times \sqrt{D C P}+2 \times \sqrt{ } A F P{ }^{58}$ According to their study, at cut off of 314.8 (75th percentile value), a low MoRAL score was associated with significantly longer recurrencefree and overall survivals in the cohort beyond the Milan criteria. The 5-year recurrence-free and overall survival rates of patients beyond the Milan criteria but with a low MoRAL score were $66.3 \%$ and $82.6 \%$, respectively, which were superior to those of the patients within the Milan criteria but with a high MoRAL score. Moreover, the patients with low MoRAL scores had significantly lower risk of tumor recurrence regardless of the presence of portal vein invasion. ${ }^{58}$

\section{Fluorine-18-flurodeoxyglucose positron emission tomography}

Hot uptake of fluorine-18-flurodeoxyglucose positron emission tomography (PET) is related to high AFP, poor differentiation, and vascular invasion. ${ }^{59-61}$ The role of fluorine-18-flurodeoxyglucose PET as a prognostic factor of HCC recurrence after LT was first demonstrated in $2006 .{ }^{59}$ The correlation between PET positivity and poor outcomes after LT has been validated in many studies subsequently. ${ }^{62-68}$ In particular, patients beyond the Milan criteria but with negative PET status could have good overall and recurrence-free survivals comparable to those within the Milan criteria. ${ }^{65,67}$ However, PET has not been integrated into candidate selection process for LT for HCC yet. The definition of PET positivity is still unclear although Lee and colleagues ${ }^{62}$ reported in 2009 that the ratio of maximal standardized uptake value (SUVmax) of tumor to SUVmax of background liver was the most significant in the prediction of HCC recurrence after $L T$, with a cutoff value of 1.15. In addition, low sensitivity in detecting HCC and high cost may be major obstacles to using PET routinely in the patient selection process for $\mathrm{LT}$.

\section{Systemic inflammatory markers}

Since it was shown that systemic inflammation could reflect tumor aggressiveness, ${ }^{69}$ various inflammatory markers have been increasingly studied worldwide as prognostic factors of malignancies. Several inflammatory markers have been suggested to be used in LT for HCC. The most frequently investigated parameter is neutrophil-to-lymphocyte ratio (NLR)..$^{70-73}$ In 2009, Halazun and colleagues $^{70}$ reported that the disease-free survival of patients with high pre-transplant NLR $\geq 5$ was significantly worse than that of patients with low NLR. In addition, the 5-year disease free survival of patients within the Milan criteria with NLR $\geq 5$ was only $30 \%$, while that of patients beyond the Milan criteria with NLR $<5$ was $60 \%{ }^{70}$ The good survival of patients beyond the Milan criteria but with low pre-transplant NLR has been demonstrated in a recent Japanese study. ${ }^{73}$ According to one recent metaanalysis, high NLR was strongly associated with poor overall survival ( $H R=3.42,95 \% \mathrm{Cl}: 2.41-4.85)$ and disease-free survival $(\mathrm{HR}=5.90,95 \% \mathrm{Cl}: 3.99-8.70)$ of HCC patients initially treated by LT. High NLR was significantly correlated with the presence of vascular invasion $(\mathrm{OR}=2.69,95 \% \mathrm{Cl}: 2.01-3.59)$, multiple tumors $(\mathrm{OR}=1.74,95 \% \mathrm{Cl}: 1.30-2.34)$ and higher incidence of $\mathrm{AFP} \geq 400$ $\mathrm{ng} / \mathrm{mL}(\mathrm{OR}=1.46,95 \% \mathrm{Cl}: 1.01-2.09)$ of $\mathrm{HCC}^{74}$ Although there are few evidences to clarify the correlation between high NLR and HCC recurrence after $L T$, data uncovered up to date support that NLR could contribute to the patient selection process. Recently, platelet-to-lymphocyte ratio (PLR) and C-reactive protein (CRP) were also investigated as predictors of HCC recurrence after LT in several studies. ${ }^{75-78}$ Lai and colleagues ${ }^{78}$ have suggested that high $P L R>150$ might be more efficacious than NLR in terms of predicting the risk of HCC recurrence after LT. One systemic review and meta-analysis showed that elevated CRP $\geq 1 \mathrm{mg} / \mathrm{dL}$ was significantly associated with the presence of tumor vascular invasion, multiple tumor, larger tumor size, and advanced stage in $\mathrm{HCC}^{79}$ An and colleagues ${ }^{75}$ have demonstrated that preoperative high CRP $\geq 1 \mathrm{mg} / \mathrm{dL}$ was an independent factor for predicting poor outcomes after LT in patients with HCC beyond the Milan criteria in terms of overall survival and recurrence-free survival. Although various systemic inflammatory markers have been suggested as possible predictors of HCC recurrence after LT, more clinical evidences should be collected before using them to select patients for LT.

\section{Response to locoregional treatment}

Because good response to locoregional treatment (LRT) reflects favorable biology of HCC, assessment of the response to pretransplant LRT can help us select suitable candidates for LT. De Carlis and colleagues ${ }^{80}$ have observed that the 5 -year recurrencefree survival rate was significantly lower for patients who experienced radiologic tumor progression after LRT compared to that 
for patients who had complete or partial response or stable disease $(93 \%$ versus $74 \%, P=0.007)$. Lai and colleagues ${ }^{81}$ have found that both radiologic progression and biologic progression (AFP slope $>15 \mathrm{ng} / \mathrm{mL} / \mathrm{month}$ ) after LRT are risk factors of poor outcomes. According to their study, patients beyond the Milan criteria without risk factors had better overall and recurrence-free survival compared to patients within the Milan criteria but with at least one risk factor. ${ }^{81}$

In DDLT, LRTs are frequently performed as a bridge strategy to decrease tumor progression during waiting time and subsequent dropout of patients on the waiting list. ${ }^{40}$ Tumor status can be changed across the Milan criteria after bridging LRTs. Some tumors beyond the Milan criteria can be down-staged within the Milan criteria after LRTs, while other tumors can progress beyond the Milan criteria even after LRTs. Interestingly, the Milan criteria reassessed after LRTs might be more predictive than the initial Milan criteria. ${ }^{82}$ In addition, post-LT outcomes for successfully downstaged patients were comparable to or even better than those of patients initially within the Milan criteria and primarily transplanted. ${ }^{83-86}$ The excellent post-LT outcomes after down-staging LRTs may be due to the fact that patients with biologically favorable tumors can be selected based on the response to LRTs. In addition, patients with initially invisible extrahepatic metastasis can be confirmed and excluded from LT during the treatment period. ${ }^{40}$

On the other hand, there is no or very short waiting time in LDLT setting. Response to LRTs cannot be sufficiently assessed in routine cases. Thus, it is difficult to use response to LRTs as a patient selection tool in LDLT. Nonetheless, pre-transplant LRTs should be considered in selected patients with morphological advanced HCC although LT might be delayed. This may help us select patients who have biologically favorable tumors and thus can benefit from LT.

\section{HOW FAR IT IS POSSIBLE TO GO FOR AD- VANCED HEPATOCELLULAR CARCINOMA}

In DDLT, liver grafts are public resources. A liberal criteria expansion for HCC would not only worsen overall outcomes of LT, but also limit the access to $\mathrm{LT}$ of patients with other liver diseases, particularly in areas with high incidence of HCC. ${ }^{15}$ However, liver grafts for LDLT are not limited by social organ allocation system because those are not public resources. In addition, liver grafts for LDLT are dedicated to only one potential recipient based on the established close donor-recipient relationship. Therefore, the over- all survival chance of the recipient and the wishes of the donor as well as the risk of recurrence after LT should be considered in LDLT setting. ${ }^{5}$

Nonetheless, the liberal expansion should be restricted even in LDLT because LDLT inevitably accompanies significant risks of donor morbidity and mortality. The associated risks of death and life-threatening complications of living donors have been reported to be as high as 0.3 and $2 \%$, respectively. ${ }^{87-89}$ Fortunately, major complication rates for living donors could be reduced by meticulous and innovative surgical techniques, increased experiencebased knowhow, and careful donor selection in high-volume LDLT centers. ${ }^{31,90}$

However, the question of 'what is the acceptable minimal estimated survival that can overcome the donor risk in LDLT?' has not been answered yet. ${ }^{5}$ This is very critical in deciding how broadly the LDLT criteria may be expanded for HCC. The acceptable target outcomes may vary from $60 \%$ or even as low as $50 \%$ of survival at 5 years post-LT to somewhere closer to that achievable under the Milan criteria. ${ }^{91}$ It certainly depends on the appropriate balance between recipient benefit and donor risk. ${ }^{5}$ LDLT is a necessary alternative to DDLT in several countries, particularly in Asia where HCC is one of the most common malignancies and there is a significant scarcity of deceased donors. ${ }^{5,92}$ Many patients with advanced HCC have fewer treatment options besides LDLT. It is not even clear if the physician has the right to deny the request of LDLT if a well-informed donor wishes to give the recipient a chance to receive the only potentially curative treatment available. Therefore, in LDLT setting, post-LT long-term expected survival of around $50 \%$ could be considered acceptable considering recipient's risk and benefit from LT as well as donor's strong desire. ${ }^{5,12,93}$

There is a limitation in expanding the criteria by means of conventional morphological factors such as the size and number of tumors. Many expanded criteria suggested up to now simply increased the threshold of morphological parameters of the Milan criteria. However, each series showed a different upper limit of the maximum diameter and the number of tumors permitted and the results were not reproducible in other institutions. ${ }^{15}$ The reason may be that the biological behavior of HCC is widely variable between patients with similar morphological tumor burden. ${ }^{15}$ In addition, only few patients could get additional chance of LT from morphological extension of the criteria as shown in a previous study comparing the Milan criteria and the UCSF criteria. ${ }^{30}$

The morphological parameters of tumors are insufficient to predict HCC recurrence after LT. The biological behavior of tumors may be widely variable between patients with similar HCC bur- 
Hae Won Lee, et al.

den..$^{15}$ Although no consensus exists regarding the use of prognostic biological parameters and the best cutoff values to adapt, the present data suggest that several biomarkers including serum AFP level, DCP level and PET positivity could have significant correlation with post-LT outcomes for HCC patients. In addition, it is well known that favorable HCCs may have excellent results after LT even if those HCCs are far advanced. Actually, we previously observed excellent post-transplant long-term survival for advanced HCC patients despite portal vein tumor thrombosis (87.5\% at 3 years) when serum AFP was $200 \mathrm{ng} / \mathrm{mL}$ or less. ${ }^{93}$ Therefore, the utilization of biological predictors may be inevitable for the selection of LT candidates for HCC, particularly for far advanced HCCs. In other words, LT could be considered even for patients with far advanced HCCs if biological predictors suggest favorable behavior of tumors and good outcomes after LT.

\section{CONCLUSION}

The Milan criteria may be too restrictive and thus exclude a significant number of HCC patients who could benefit from LT. However, in DDLT setting, liberal criteria expansion should be restricted because LT for HCC could be justified only when results are comparable to those of patients with non-malignant indications. On the other hand, in LDLT situation, post-LT expected survival of around $50 \%$ could be acceptable if a well-informed donor wishes to give the only chance of cure to the recipient.

The significance of biological parameters in predicting HCC recurrence after LT is increasing. Excellent outcomes could be expected even for patients with far advanced HCCs if several biomarkers such as AFP level, DCP level or PET indicate favorable tumor biology. In the near future, we could increase the number of transplantable HCC patients effectively and safely by adding biological parameters to conventional morphological factors. However, further studies are needed to reach an international consensus on the application of biomarkers for the selection of LT for HCC.

\section{Conflicts of Interest}

The authors have no conflicts to disclose.

\section{REFERENCES}

1. Lai Q, Lerut JP. Hepatocellular cancer: how to expand safely inclu- sion criteria for liver transplantation. Curr Opin Organ Transplant 2014;19:229-234.

2. Pichlmayr R, Weimann A, Ringe B. Indications for liver transplantation in hepatobiliary malignancy. Hepatology 1994;20:33S-40S.

3. Menon KV, Hakeem AR, Heaton ND. Review article: liver transplantation for hepatocellular carcinoma - a critical appraisal of the current worldwide listing criteria. Aliment Pharmacol Ther 2014;40:893-902.

4. Bruix J, Sherman M.Management of hepatocellular carcinoma. Hepatology 2005;42:1208-1236.

5. Lee HW, Suh KS. Expansion of the criteria for living donor liver transplantation for hepatocellular carcinoma. Curr Opin Organ Transplant 2016;21:231-237.

6. Mazzaferro V, Regalia E, Doci R, Andreola S, Pulvirenti A, Bozzetti F, et al. Liver transplantation for the treatment of small hepatocellular carcinomas in patients with cirrhosis. N Engl J Med 1996;334:693-699.

7. Iwatsuki S, Gordon RD, Shaw BW, Jr., Starzl TE. Role of liver transplantation in cancer therapy. Ann Surg 1985;202:401-407.

8. O'Grady JG, Polson RJ, Rolles K, Calne RY, Williams R. Liver transplantation for malignant disease. Results in 93 consecutive patients. Ann Surg 1988;207:373-379.

9. Iwatsuki S, Starzl TE, Sheahan DG, Yokoyama I, Demetris AJ, Todo $S$, et al. Hepatic resection versus transplantation for hepatocellular carcinoma. Ann Surg 1991;214:221-228; discussion 228-229.

10. Penn I. Hepatic transplantation for primary and metastatic cancers of the liver. Surgery 1991;110:726-734.

11. Bismuth H, Chiche L, Adam R, Castaing D, Diamond T, Dennison A. Liver resection versus transplantation for hepatocellular carcinoma in cirrhotic patients. Ann Surg 1993;218:145-151.

12. Kumaran V. Role of liver transplantation for hepatocellular carcinoma. J Clin Exp Hepatol 2014;49(Suppl 3):S97-S103.

13. Mazzaferro V, Bhoori S, Sposito C, Bongini M, Langer M, Miceli R, et al. Milan criteria in liver transplantation for hepatocellular carcinoma: an evidence-based analysis of 15 years of experience. Liver Transpl 2011;17(Suppl 2):S44-S57.

14. Ulahannan SV, Duffy AG, McNeel TS, Kish JK, Dickie LA, Rahma OE, et al. Earlier presentation and application of curative treatments in hepatocellular carcinoma. Hepatology 2014;60:1637-1644.

15. Guerrero-Misas M, Rodríguez-Perálvarez M, De la Mata M. Strategies to improve outcome of patients with hepatocellular carcinoma receiving a liver transplantation. World J Hepatol 2015;7:649-661.

16. Silva MF, Sherman M. Criteria for liver transplantation for HCC: what should the limits be? J Hepatol 2011;55:1137-1147.

17. Yao FY, Xiao L, Bass NM, Kerlan R, Ascher NL, Roberts JP. Liver transplantation for hepatocellular carcinoma: validation of the UCSF-expanded criteria based on preoperative imaging. Am J Transplant 2007;7:2587-2596.

18. Mazzaferro V, Llovet JM, Miceli R, Bhoori S, Schiavo M, Mariani L, 
et al. Predicting survival after liver transplantation in patients with hepatocellular carcinoma beyond the Milan criteria: a retrospective, exploratory analysis. Lancet Oncol 2009;10:35-43.

19. Herrero JI, Sangro B, Pardo F, Quiroga J, Iñarrairaegui M, Rotellar F, et al. Liver transplantation in patients with hepatocellular carcinoma across Milan criteria. Liver Transpl 2008;14:272-278.

20. Silva M, Moya A, Berenguer $M$, Sanjuan F, López-Andujar R, Pareja $E$, et al. Expanded criteria for liver transplantation in patients with cirrhosis and hepatocellular carcinoma. Liver Transpl 2008;14:1449-1460.

21. Lee SG, Hwang S, Moon DB, Ahn CS, Kim KH, Sung KB, et al. Expanded indication criteria of living donor liver transplantation for hepatocellular carcinoma at one large-volume center. Liver Transpl 2008;14:935-945.

22. Toso C, Trotter J, Wei A, Bigam DL, Shah S, Lancaster J, et al. Total tumor volume predicts risk of recurrence following liver transplantation in patients with hepatocellular carcinoma. Liver Transpl 2008;14:1107-1115.

23. Zheng SS, Xu X, Wu J, Chen J, Wang WL, Zhang M, et al. Liver transplantation for hepatocellular carcinoma: Hangzhou experiences. Transplantation 2008;85:1726-1732.

24. DuBay D, Sandroussi C, Sandhu L, Cleary S, Guba M, Cattral MS, et al. Liver transplantation for advanced hepatocellular carcinoma using poor tumor differentiation on biopsy as an exclusion criterion. Ann Surg 2011;253:166-172.

25. Shirabe K, Taketomi A, Morita K, Soejima Y, Uchiyama H, Kayashima $\mathrm{H}$, et al. Comparative evaluation of expanded criteria for patients with hepatocellular carcinoma beyond the Milan criteria undergoing living-related donor liver transplantation. Clin Transplant 2011;25:E491-E498.

26. Kaido T, Ogawa K, Mori A, Fujimoto Y, Ito T, Tomiyama K, et al. Usefulness of the Kyoto criteria as expanded selection criteria for liver transplantation for hepatocellular carcinoma. Surgery 2013;154:1053-1060.

27. Akamatsu N, Sugawara Y, Kokudo N. Living donor liver transplantation for patients with hepatocellular carcinoma. Liver Cancer 2014;3:108-118.

28. Kim JM, Kwon CH, Joh JW, Park JB, Lee JH, Kim GS, et al. Expanded criteria for liver transplantation in patients with hepatocellular carcinoma. Transplant Proc 2014;46:726-729.

29. Yao FY, Ferrell L, Bass NM, Watson JJ, Bacchetti P, Venook A, et al. Liver transplantation for hepatocellular carcinoma: expansion of the tumor size limits does not adversely impact survival. Hepatology 2001;33:1394-1403.

30. Patel SS, Arrington AK, McKenzie S, Mailey B, Ding M, Lee W, et al. Milan Criteria and UCSF Criteria: A Preliminary Comparative Study of Liver Transplantation Outcomes in the United States Int J Hepatol 2012;2012:253517.

31. Song GW, Lee SG. Living donor liver transplantation. Curr Opin Or- gan Transplant 2014;19:217-222.

32. Cillo U, Giuliani T, Polacco M, Herrero Manley LM, Crivellari G, Vitale A. Prediction of hepatocellular carcinoma biological behavior in patient selection for liver transplantation. World J Gastroenterol 2016;22:232-252.

33. Hemming AW, Cattral MS, Reed Al, Van Der Werf WJ, Greig PD, Howard RJ. Liver transplantation for hepatocellular carcinoma. Ann Surg 2001;233:652-659.

34. Jonas S, Bechstein WO, Steinmüller T, Herrmann M, Radke C, Berg $T$, et al. Vascular invasion and histopathologic grading determine outcome after liver transplantation for hepatocellular carcinoma in cirrhosis. Hepatology 2001;33:1080-1086.

35. Tamura S, Kato T, Berho M, Misiakos EP, O'Brien C, Reddy KR, et al. Impact of histological grade of hepatocellular carcinoma on the outcome of liver transplantation. Arch Surg 2001;136:25-30.

36. Cillo U, Vitale A, Bassanello M, Boccagni P, Brolese A, Zanus G, et al. Liver transplantation for the treatment of moderately or welldifferentiated hepatocellular carcinoma. Ann Surg 2004;239:150-159.

37. Saborido BP, Díaz JC, de Los Galanes SJ, Segurola CL, de Usera MA, Garrido MD, et al. Does preoperative fine needle aspiration-biopsy produce tumor recurrence in patients following liver transplantation for hepatocellular carcinoma? Transplant Proc 2005;37:3874-3877.

38. Silva MA, Hegab B, Hyde C, Guo B, Buckels JA, Mirza DF. Needle track seeding following biopsy of liver lesions in the diagnosis of hepatocellular cancer: a systematic review and meta-analysis. Gut 2008:57:1592-1596.

39. Clavien PA, Lesurtel M, Bossuyt PM, Gores GJ, Langer B, Perrier A, et al. Recommendations for liver transplantation for hepatocellular carcinoma: an international consensus conference report. Lancet Oncol 2012;13:e11-e22.

40. Takada Y, Tohyama T, Watanabe J. Biological markers of hepatocellular carcinoma for use as selection criteria in liver transplantation. J Hepatobiliary Pancreat Sci 2015;22:279-286.

41. Suh KS, Cho EH, Lee HW, Shin WY, Yi NJ, Lee KU. Liver transplantation for hepatocellular carcinoma in patients who do not meet the Milan criteria. Dig Dis 2007;25:329-333.

42. Yang SH, Suh KS, Lee HW, Cho EH, Cho JY, Cho YB, et al. A revised scoring system utilizing serum alphafetoprotein levels to expand candidates for living donor transplantation in hepatocellular carcinoma. Surgery 2007;141:598-609.

43. Toso C, Asthana S, Bigam DL, Shapiro AM, Kneteman NM. Reassessing selection criteria prior to liver transplantation for hepatocellular carcinoma utilizing the Scientific Registry of Transplant Recipients database. Hepatology 2009;49:832-838.

44. Duvoux C, Roudot-Thoraval F, Decaens T, Pessione F, Badran H, Piardi $T$, et al. Liver transplantation for hepatocellular carcinoma: a model including alpha-fetoprotein improves the performance of Milan criteria. Gastroenterology 2012;143:986-994. 
Hae Won Lee, et al. Liver transplantation for advanced $\mathrm{HCC}$

45. Tanaka T, Kurosaki M, Lilly LB, Izumi N, Sherman M. Identifying candidates with favorable prognosis following liver transplantation for hepatocellular carcinoma: Data mining analysis. J Surg Oncol 2015:112:72-79.

46. Levi DM, Tzakis AG, Martin P, Nishida S, Island E, Moon J, et al. Liver transplantation for hepatocellular carcinoma in the model for endstage liver disease era. J Am Coll Surg 2010;210:727-734, 735-726.

47. Merani S, Majno P, Kneteman NM, Berney T, Morel P, Mentha G, et al. The impact of waiting list alpha-fetoprotein changes on the outcome of liver transplant for hepatocellular carcinoma. J Hepatol 2011;55:814-819.

48. Wong LL, Naugler WE, Schwartz J, Scott DL, Bhattacharya R, Reyes J, et al. Impact of locoregional therapy and alpha-fetoprotein on outcomes in transplantation for liver cancer: a UNOS Region 6 pooled analysis. Clin Transplant 2013;27:E72-E79.

49. Han K, Tzimas GN, Barkun JS, Metrakos P, Tchervenkov JL, Hilzenrat $\mathrm{N}$, et al. Preoperative alpha-fetoprotein slope is predictive of hepatocellular carcinoma recurrence after liver transplantation. Can J Gastroenterol 2007;21:39-45.

50. Vibert E, Azoulay D, Hoti E, lacopinelli S, Samuel D, Salloum C, et al. Progression of alphafetoprotein before liver transplantation for hepatocellular carcinoma in cirrhotic patients: a critical factor. Am J Transplant 2010;10:129-137.

51. Dumitra TC, Dumitra S, Metrakos PP, Barkun JS, Chaudhury P, Deschênes $M$, et al. Pretransplantation alpha-fetoprotein slope and milan criteria: strong predictors of hepatocellular carcinoma recurrence after transplantation. Transplantation 2013;95:228-233.

52. Shirabe K, Kajiyama K, Abe T, Sakamoto S, Fukuya T, Akazawa K, et al. Predictors of microscopic portal vein invasion by hepatocellular carcinoma: measurement of portal perfusion defect area ratio. J Gastroenterol Hepatol 2009;24:1431-1436.

53. Eguchi S, Takatsuki M, Hidaka M, Soyama A, Tomonaga T, Muraoka I, et al. Predictor for histological microvascular invasion of hepatocellular carcinoma: a lesson from 229 consecutive cases of curative liver resection. World J Surg 2010;34:1034-1038.

54. Kaibori M, Ishizaki M, Matsui K, Kwon AH. Predictors of microvascular invasion before hepatectomy for hepatocellular carcinoma. J Surg Oncol 2010;102:462-468.

55. Fujiki M, Takada Y, Ogura Y, Oike F, Kaido T, Teramukai S, et al. Significance of des-gamma-carboxy prothrombin in selection criteria for living donor liver transplantation for hepatocellular carcinoma. Am J Transplant 2009;9:2362-2371.

56. Taketomi A, Sanefuji K, Soejima Y, Yoshizumi T, Uhciyama H, Ikegami $T$, et al. Impact of des-gamma-carboxy prothrombin and tumor size on the recurrence of hepatocellular carcinoma after living donor liver transplantation. Transplantation 2009;87:531-537.

57. Shindoh J, Sugawara Y, Nagata R, Kaneko J, Tamura S, Aoki T, et al. Evaluation methods for pretransplant oncologic markers and their prognostic impacts in patient undergoing living donor liver transplantation for hepatocellular carcinoma. Transpl Int 2014;27:391-398.

58. Lee JH, Cho Y, Kim HY, Cho EJ, Lee DH, Yu SJ, et al. Serum Tumor Markers Provide Refined Prognostication in Selecting Liver Transplantation Candidate for Hepatocellular Carcinoma Patients Beyond the Milan Criteria. Ann Surg 2016;263:842-850.

59. Yang SH, Suh KS, Lee HW, Cho EH, Cho JY, Cho YB, et al. The role of (18)F-FDG-PET imaging for the selection of liver transplantation candidates among hepatocellular carcinoma patients. Liver Transpl 2006;12:1655-1660.

60. Seo S, Hatano E, Higashi T, Hara T, Tada M, Tamaki N, et al. Fluorine-18 fluorodeoxyglucose positron emission tomography predicts tumor differentiation, P-glycoprotein expression, and outcome after resection in hepatocellular carcinoma. Clin Cancer Res 2007:13:427-433.

61. Kornberg A, Freesmeyer M, Barthel E, Jandt K, Katenkamp K, Steenbeck J, et al. 18F-FDG-uptake of hepatocellular carcinoma on PET predicts microvascular tumor invasion in liver transplant patients. Am J Transplant 2009;9:592-600.

62. Lee JW, Paeng JC, Kang KW, Kwon HW, Suh KS, Chung JK, et al. Prediction of tumor recurrence by $18 \mathrm{~F}-\mathrm{FDG}$ PET in liver transplantation for hepatocellular carcinoma. J Nucl Med 2009;50:682-687.

63. Lee S, Ahn C, Ha T, Moon D, Choi K, Song G, et al. Liver transplantation for hepatocellular carcinoma: Korean experience. J Hepatobiliary Pancreat Sci 2010;17:539-547.

64. Cheung TT, Chan SC, Ho CL, Chok KS, Chan AC, Sharr WW, et al. Can positron emission tomography with the dual tracers [11 C] acetate and [18 F]fludeoxyglucose predict microvascular invasion in hepatocellular carcinoma? Liver Transpl 2011;17:1218-1225.

65. Kornberg A, Küpper B, Tannapfel A, Büchler P, Krause B, Witt U, et al. Patients with non-[18 F]fludeoxyglucose-avid advanced hepatocellular carcinoma on clinical staging may achieve long-term recurrence-free survival after liver transplantation. Liver Transpl 2012;18:53-61.

66. Lee SD, Kim SH, Kim YK, Kim C, Kim SK, Han SS, et al. (18)F-FDG$\mathrm{PET} / \mathrm{CT}$ predicts early tumor recurrence in living donor liver transplantation for hepatocellular carcinoma. Transpl Int 2013;26:50-60.

67. Lee SD, Kim SH, Kim SK, Kim YK, Park SJ. Clinical Impact of 18FFluorodeoxyglucose Positron Emission Tomography/Computed Tomography in Living Donor Liver Transplantation for Advanced Hepatocellular Carcinoma. Transplantation 2015;99:2142-2149.

68. Hong G, Suh KS, Suh SW, Yoo T, Kim H, Park MS, et al. Alpha-fetoprotein and (18)F-FDG positron emission tomography predict tumor recurrence better than Milan criteria in living donor liver transplantation. J Hepatol 2016;64:852-859.

69. Tan TT, Coussens LM. Humoral immunity, inflammation and cancer. Curr Opin Immunol 2007;19:209-216.

70. Halazun KJ, Hardy MA, Rana AA, Woodland DC 4th, Luyten EJ, Mahadev $S$, et al. Negative impact of neutrophil-lymphocyte ratio 
on outcome after liver transplantation for hepatocellular carcinoma. Ann Surg 2009;250:141-151.

71. Bertuzzo VR, Cescon M, Ravaioli M, Grazi GL, Ercolani G, Del Gaudio $\mathrm{M}$, et al. Analysis of factors affecting recurrence of hepatocellular carcinoma after liver transplantation with a special focus on inflammation markers. Transplantation 2011;91:1279-1285.

72. Limaye AR, Clark V, Soldevila-Pico C, Morelli G, Suman A, Firpi R, et al. Neutrophil-lymphocyte ratio predicts overall and recurrencefree survival after liver transplantation for hepatocellular carcinoma. Hepatol Res 2013;43:757-764.

73. Motomura T, Shirabe K, Mano Y, Muto J, Toshima T, Umemoto $Y$, et al. Neutrophil-lymphocyte ratio reflects hepatocellular carcinoma recurrence after liver transplantation via inflammatory microenvironment. J Hepatol 2013;58:58-64.

74. Xiao WK, Chen D, Li SQ, Fu SJ, Peng BG, Liang LJ. Prognostic significance of neutrophil-lymphocyte ratio in hepatocellular carcinoma: a meta-analysis. BMC Cancer 2014;14:117.

75. An HJ, Jang JW, Bae SH, Choi JY, Yoon SK, Lee MA, et al. Serum Creactive protein is a useful biomarker for predicting outcomes after liver transplantation in patients with hepatocellular carcinoma. Liver Transpl 2012;18:1406-1414.

76. Mori S, Choi Y, Park MS, Kim H, Hong G, Yi NJ, et al. Usefulness of preoperative C-reactive protein and alpha-fetoprotein levels for prognostication of patients with hepatocellular carcinoma after living donor liver transplantation. Hepatogastroenterology 2014;61:2353-2358

77. Xia W, Ke Q, Wang Y, Wang W, Zhang M, Shen Y, et al. Predictive value of pre-transplant platelet to lymphocyte ratio for hepatocelIular carcinoma recurrence after liver transplantation. World J Surg Oncol 2015;13:60.

78. Lai Q, Castro Santa E, Rico Juri JM, Pinheiro RS, Lerut J. Neutrophil and platelet-to-lymphocyte ratio as new predictors of dropout and recurrence after liver transplantation for hepatocellular cancer. Transpl Int 2014;27:32-41.

79. Zheng Z, Zhou L, Gao S, Yang Z, Yao J, Zheng S. Prognostic role of C-reactive protein in hepatocellular carcinoma: a systematic review and meta-analysis. Int J Med Sci 2013;10:653-664.

80. De Carlis L, Di Sandro S, Giacomoni A, Slim A, Lauterio A, Mangoni I, et al. Beyond the Milan criteria: what risks for patients with hepatocellular carcinoma progression before liver transplantation? J Clin Gastroenterol 2012;46:78-86.

81. Lai Q, Avolio AW, Graziadei I, Otto G, Rossi M, Tisone G, et al. Alpha-fetoprotein and modified response evaluation criteria in solid tumors progression after locoregional therapy as predictors of hepatocellular cancer recurrence and death after transplantation. Liver Transpl 2013;19:1108-1118.

82. Otto G, Schuchmann M, Hoppe-Lotichius $M$, Heise M, Weinmann A, Hansen $T$, et al. How to decide about liver transplantation in patients with hepatocellular carcinoma: size and number of lesions or response to TACE? J Hepatol 2013;59:279-284.

83. Yao FY, Kerlan RK Jr, Hirose R, Davern TJ 3rd, Bass NM, Feng S, et al. Excellent outcome following down-staging of hepatocellular carcinoma prior to liver transplantation: an intention-to-treat analysis. Hepatology 2008;48:819-827.

84. Chapman WC, Majella Doyle MB, Stuart JE, Vachharajani N, Crippin $J S$, Anderson $C D$, et al. Outcomes of neoadjuvant transarterial chemoembolization to downstage hepatocellular carcinoma before liver transplantation. Ann Surg 2008;248:617-625.

85. Ravaioli M, Grazi GL, Piscaglia F, Trevisani F, Cescon M, Ercolani G, et al. Liver transplantation for hepatocellular carcinoma: results of down-staging in patients initially outside the Milan selection criteria. Am J Transplant 2008;8:2547-2557.

86. De Luna W, Sze DY, Ahmed A, Ha BY, Ayoub W, Keeffe EB, et al. Transarterial chemoinfusion for hepatocellular carcinoma as downstaging therapy and a bridge toward liver transplantation. Am J Transplant 2009;9:1158-1168.

87. Ghobrial RM, Freise CE, Trotter JF, Tong L, Ojo AO, Fair JH, et al Donor morbidity after living donation for liver transplantation. Gastroenterology 2008;135:468-476.

88. Brown RS, Jr. Live donors in liver transplantation. Gastroenterology 2008;134:1802-1813.

89. Cheah YL, Simpson MA, Pomposelli JJ, Pomfret EA. Incidence of death and potentially life-threatening near-miss events in living donor hepatic lobectomy: a world-wide survey. Liver Transpl 2013;19:499-506.

90. Azoulay D, Bhangui P, Andreani P, Salloum C, Karam V, Hoti E, et al. Short- and long-term donor morbidity in right lobe living donor liver transplantation: 91 consecutive cases in a European Center. Am J Transplant 2011;11:101-110.

91. Tamura S, Sugawara Y, Kokudo N. Section 4. Further expanding the criteria for HCC in living donor liver transplantation: the Tokyo University experience. Transplantation 2014;97(Suppl 8):S17-S20.

92. Azzam AZ. Liver transplantation as a management of hepatocellular carcinoma. World J Hepatol 2015;7:1347-1354.

93. Suh KS, Lee HW. Liver transplantation for advanced hepatocellular carcinoma: how far can we go? Hepat Oncol 2015;2:19-28. 